\title{
Coronary Revascularization After Intravenous Tissue Plasminogen Activator for Unstable Angina Pectoris: Results of a Randomized, Double-Blind, Placebo-Controlled Trial
}

\author{
Eric J. Topol, MD, John M. Nicklas, MD, Nathan H. Kander, MD, Joseph A. Walton, MD, \\ Stephen G. Ellis, MD, Laura Gorman, RN, and Bertram Pitt, MD
}

To determine the role of intravenous tissue plasminogen activator (t-PA) in unstable angina, it was compared with placebo in a randomized, doubleblind trial. Forty patients with angina at rest and provocable ischemia (pacing induced) had baseline coronary angiography, study drug infusion and then repeat angiography at $\mathbf{2 0} \pm \mathbf{9}$ hours. All patients received diltiazem, nitrates, $\beta$ blockers, aspirin and intravenous heparin. During study drug infusion (150 mg over 8 hours), refractory ischemia necessitating emergency bypass surgery (CABG) or coronary angioplasty (PTCA) occurred in 4 of 20 t-PA patients compared with 1 of 20 placebo patients $(p=0.21$ ). Before discharge, revascularization for persistent, provocable ischemia and a residual stenosis $\geq 60 \%$ was as follows: t-PA patients, 8 PTCA and 7 CABG; placebo patients, 11 PTCA and 8 CABG $(p=0.39)$. Quantitative angiographic percent diameter stenosis of the culprit artery at baseline and follow-up was: t-PA $71 \pm 17$ and $63 \pm$ 22; placebo $70 \pm 19$ and $67 \pm 22$ (difference not significant). However, 3 t-PA patients compared with no placebo patients demonstrated an insignificant ( $<60 \%$ diameter) residual stenosis and averted PTCA $(p=0.14)$. There were no complications of PTCA in the 8 t-PA patients; in contrast, 3 of 11 placebo patients had abrupt closure, necessilating emergency CABG in 2 ( $p=0.23$ ). Thus, intravenous t-PA in unstable angina can eliminate the need for PTCA in a few patients, does not appear to decrease the overall or emergency rate of revascularization procedures and may facilltate the safety of PTCA.

(Am J Cardiol 1988;62:368-371)

From the Division of Cardiology, Department of Internal Medicine, University of Michigan Medical Center, Ann Arbor, Michigan. This study was supported in part by Genentech, Inc., South San Francisco, California. Manuscript received January 21, 1988; revised manuscript received April 7, 1988, and accepted April 23.

Address for rcprints: Eric J. Topol, MD, Cardiac Catheterization Laboratories, B1-F245 University Hospital, 1500 East Medical Center Drive, Ann Arbor, Michigan 48109.
$\mathrm{T}$ The critical importance of coronary artery thrombus in the clinical syndrome of unstable angina has been well established by recent biochemical, angiographic, angioscopic and pathologic studies. ${ }^{1-4} \mathrm{De}-$ spite our increased understanding of the pathophysiology, there has been limited experience with thrombolytic therapy for unstable angina ${ }^{5-7}$ and the results obtained to date lack agreement regarding the indications or usefulness of such therapy. Since its introduction for management of unstable angina in $1981,8,9$ percutaneous transluminal coronary angioplasty (PTCA) has been increasingly applied, particularly for refractory symptoms..$^{10}$ However, angiographically defined thrombus, a common feature of unstable angina and rest ischemic pain, has been identified as a risk factor for abrupt closure and complications of PTCA. ${ }^{11}$ Thus, the rationale for thrombolytic therapy in this setting extends beyond dissolution of intraluminal coronary artery thrombus, to the potential achievement or facilitation of definitive coronary revascularization. The current study was designed to evaluate intravenous tissue-type plasminogen activator (t-PA), a relatively clot-selective fibrinolytic agent with particular advantage for aged thrombus ${ }^{12}$ in patients with unstable angina receiving maximal medical therapy. In this randomized, double-blind pilot trial report, the focus will be the need for coronary revascularization procedures and their safety following intravenous t-PA or placebo.

\section{METHODS}

Patient selection: Inclusion criteria were: (1) chest pain at rest within 7 days judged clinically to represent myocardial ischemia, with or without accompanying electrocardiographic changes; (2) angiographically defined significant coronary artery stenosis $(>60 \%$ diameter by visual estimate); (3) provocation of ischemia by pacing; and (4) absence of a contraindication to thrombolytic therapy, left main coronary artery stenosis $>50 \%$ or recent myocardial infarction, as indicated by elevation of serum creatine phosphokinase 2 times above normal levels. Informed consent was obtained before enrollment. Recruitment began on March 26, 1986, and ended on April 1, 1987.

Treatment protocol: Before cardiac catheterization 5-drug medical therapy was initiated and maximized as follows: (1) aspirin $325 \mathrm{mg}$ daily; (2) propranolol $40 \mathrm{mg}$ 
4 times daily (or an alternate $\beta$-blocking agent) or higher doses to decrease resting heart rate no lower than 50 beats/min; (3) diltiazem 60 to $120 \mathrm{mg} 4$ times daily; (4) intravenous nitroglycerin or oral isosorbide dinitrate every 6 hours (unless systolic blood pressure $<110 \mathrm{~mm}$ $\mathrm{Hg}$ ); and (5) intravenous heparin 1,000 U/hr continuous infusion adjusted to 2 to 2.5 times the activated partial thromboplastin time. After diagnostic coronary angiography using the Judkins approach, transvenous right ventricular pacing was begun at 70 to 100 beats/ min and serially increased at 3-minute intervals by increments of 10 beats/min until the patient developed typical anginal chest pain, significant ST-segment changes ( $>1.5 \mathrm{mV}$ depression) by 12-lead electrocardiography during supraventricular rhythm between rate increases or until reaching a rate of 150 beats $/ \mathrm{min}$. Femoral arterial and venous sheaths were left in place for repeat angiographic and pacing studies.

Patients fulfilling entry criteria were randomly allocated to receive t-PA or placebo by a random number sequence developed by Genentech, unknown to the investigators, until the completion of the trial and all data entry. The study drug vials were physically identical and a sealed envelope, containing a scratch-away film card, were provided for each patient in case of medical emergency. The dose of intravenous t-PA (predominantly single chain preparation, Genentech, Inc.) was $60 \mathrm{mg}$ over the first hour, with $6 \mathrm{mg}$ as a bolus, $20 \mathrm{mg} /$ hr each for 2 hours, then $10 \mathrm{mg} / \mathrm{hr}$ for 5 hours, for a total dose of $150 \mathrm{mg}$. Patients were continuously monitored for chest pain and considered to reach a clinical endpoint if more than 20 minutes of chest pain occurred, unresponsive to further medical therapy, and was associated with electrocardiographic changes. If this occurred, the study drug was unblinded and in cases of placebo, the patient was considered for crossover to open label t-PA therapy, as outlined. Emergency coronary revascularization with either PTCA or $\mathrm{CABG}$ was used as necessary to treat recurrent ischemic events.

Follow-up angiography was obtained at 12 to 24 hours after the initial study. A repeat pacing test was performed. If a significant $(\geq 60 \%)$ residual stenosis of the "culprit" vessel ${ }^{13}$ was present and the pacing test was positive for provocable ischemia, coronary revascularization was considered to be necessary. Coronary angioplasty or bypass surgery was performed, depending on the underlying coronary anatomy. Results and complications of the revascularization procedures were recorded. Subsequent to the second angiogram, off-line quantitative angiography was performed for the culprit artery at baseline, after study drug, and after PTCA, if performed, using an automated edge detection computer algorithm. ${ }^{14}$ Angiographic thrombus was defined as a definite intracoronary filling defect in at least 2 orthogonal views or total occlusion of the involved artery with convex or hazy margins and contrast staining. Quantitative stenosis and the presence of intraluminal thrombus were determined by 2 observers blinded to the patient's identity, therapy and effects of therapy.

\begin{tabular}{|c|c|c|}
\hline & $\mathrm{t}-\mathrm{PA}$ & Placebo \\
\hline Pts (n) & 20 & 20 \\
\hline Age (yrs) & $58.8 \pm 2.5$ & $58.1 \pm 2.2$ \\
\hline Sex $(\%$ male $)$ & 75 & 65 \\
\hline Previous MI & 6 & 8 \\
\hline Multivessel disease $^{\dagger}$ & 15 & 11 \\
\hline Duration unstable angina (days) & $8.8 \pm 1.7$ & $6.6 \pm 1.4$ \\
\hline Intracoronary thrombus & 7 & 9 \\
\hline Ischemic pacing threshold (beats/min) & $112 \pm 4$ & $113 \pm 5$ \\
\hline Diameter stenosis (\%) culprit lesion ${ }^{\ddagger}$ & $71 \pm 4$ & $70 \pm 4$ \\
\hline \multicolumn{3}{|l|}{ Culprit vessel } \\
\hline Left anterior descending & 11 & 11 \\
\hline Left circumflex & 5 & 4 \\
\hline Right coronary artery & 3 & 5 \\
\hline Saphenous vein graft & 1 & 0 \\
\hline \multicolumn{3}{|c|}{$\begin{array}{l}\text { There were no significant differences }(p<0.05) \text { between the } 2 \text { groups tor any } \\
\text { baseline characteristic; }{ }^{\dagger} \text { multivessel disease was defined as } \geq 60 \% \text { stenosis in a } \\
\text { nonculprit, major epicardial coronary artery: }{ }^{\ddagger} \text { by quantitative angiography. } \\
\mathrm{MI}=\text { myocardial infarction. }\end{array}$} \\
\hline
\end{tabular}

Values are expressed as mean \pm 1 standard deviation. Characteristics at baseline and clinical outcomes were tabulated and compared by the chi-square test or Fisher's exact test for discrete variables and the Student $t$ test for continuous characteristics. Clinical endpoints were assessed with use of the intention-to-treat principle. A sample group of 40 patients was used to determine the pacing threshold endpoint, and is the subject of a separate report. ${ }^{15}$

\section{RESULTS}

Baseline characteristics are summarized in Table $\mathbf{I}$. Of note, the groups were similar for initial quantitative stenosis of the culprit lesion and for pacing ischemic threshold. During the course of therapy, 4 patients allocated to receive t-PA and 1 to placebo developed refractory ischemia. Of the patients who received t-PA, 1 died before urgent repeat angiography, and another died after emergency CABG. The placebo group patient with refractory ischemia failed emergency PTCA and underwent emergency $\mathrm{CABG}$.

At repeat coronary arteriography, the diameter stenosis of the culprit artery was $63 \pm 22 \%$ in the patients receiving t-PA versus $67 \pm 22 \%$ in placebo group patients $(\mathrm{p}=0.20)$. The pacing threshold results have been previously reported..$^{15}$ To summarize, the threshold significantly increased for the patients receiving t-PA ( $112 \pm 4$ beats/min at baseline, mean \pm standard error of the mean; $127 \pm 5$ beats $/ \mathrm{min}$ after therapy, $\mathrm{p}=$ $0.007)$ and did not change in the control group (116 \pm 4 beats/min at baseline; $119 \pm 4$ beats/min after study drug infusion). The patients with angiographically defined thrombus experienced the most substantial increase in pacing threshold (increase of $26 \pm 7$ beats/ min in patients receiving t-PA vs $0 \pm 3$ beats $/ \mathrm{min}$ in controls, $p=0.004)$.

The cumulative rate for coronary revascularization procedures, as established by a significant residual stenosis and a positive test result for pacing-induced ischemia at follow-up catheterization, is as follows: t-PA patients, 3 emergency $\mathrm{CABG}, 4$ elective $\mathrm{CABG}$ and 8 
elective PTCA; placebo patients, 1 emergency $\mathrm{CABG}, 7$ elective $\mathrm{CABG}$ and 11 elective PTCA. In the placcbo group, 2 patients underwent both elective PTCA and emergency $\mathrm{CABG}$. No significant differences in overall rate of PTCA or CABG were present for t-PA compared with placebo. However, 3 patients treated with $t-$ PA compared with none receiving placebo had conversion to an insignificant residual stenosis $(<60 \%$ diameter by visual criteria) and a ncgative pacing test $(\mathrm{p}=$ 0.14).

During PTCA, no patient receiving t-PA experienced a complication of abrupt closure and 7 of 8 were successful, as defined by $<50 \%$ residual stenosis and $<20 \mathrm{~mm} \mathrm{Hg}$ translesional gradient (Figure 1). This compares favorably to the 11 placebo group patients who underwent PTCA, of whom 3 had abrupt closure post-PTCA that could not be managed by pharmacologic (intracoronary nitroglycerin and streptokinase) or mechanical means (prolonged inflations with a $0.5 \mathrm{~mm}$ larger size balloon at 4 to 6 atmospheres), in 2 patients necessitating emergency CABG $(p=0.23)$. In all 3 patients with abrupt closure, filling defects, suggestive of intraluminal thrombus formation, were apparent after recrossing the lesion and reestablishing flow. The remaining 8 placebo group patients had successful PTCA.

Bleeding episodes with t-PA or the control group patients were not frequent. Periaccess bleeding occurred in 3 t-PA patients and 2 patients who received placebo.
Transfusion of 2 or more units of packed cells occurred in $5 \mathrm{t}$-PA patients and no control group patient. The indication for transfusion in 4 of the 5 patients receiving t-PA was augmentation of hematocrit and in 1 patient for observed periaccess site bleeding.

\section{DISCUSSION}

The results of the current study of intravenous t-PA for unstable angina demonstrate the overall high frequency of definitive coronary revascularization procedures, but also suggest that t-PA may serve as complete therapy in a few patients. Importantly, t-PA appeared to promote the safety of the PTCA procedure beyond maximal medical therapy including heparin. The conclusions drawn must be tempered, however, due to the small population studied.

Previous angiographic, angioscopic and pathologic studies $^{2-4}$ have documented the importance of coronary artery thrombus in unstable angina, but the relative, quantitative impact of thrombus compared with the underlying atherosclerotic plaque remains unclear. After a prolonged, high dose infusion of t-PA, the fibrinolytic agent with the highest potential to lyse aged thrombus, ${ }^{12}$ only slight improvement of quantitative angiographic stenosis was present and most patients had persistently positive albeit improved tests for provocable (pacing-induced) ischemia. These findings suggest that although thrombus plays an integral role for precipitat-

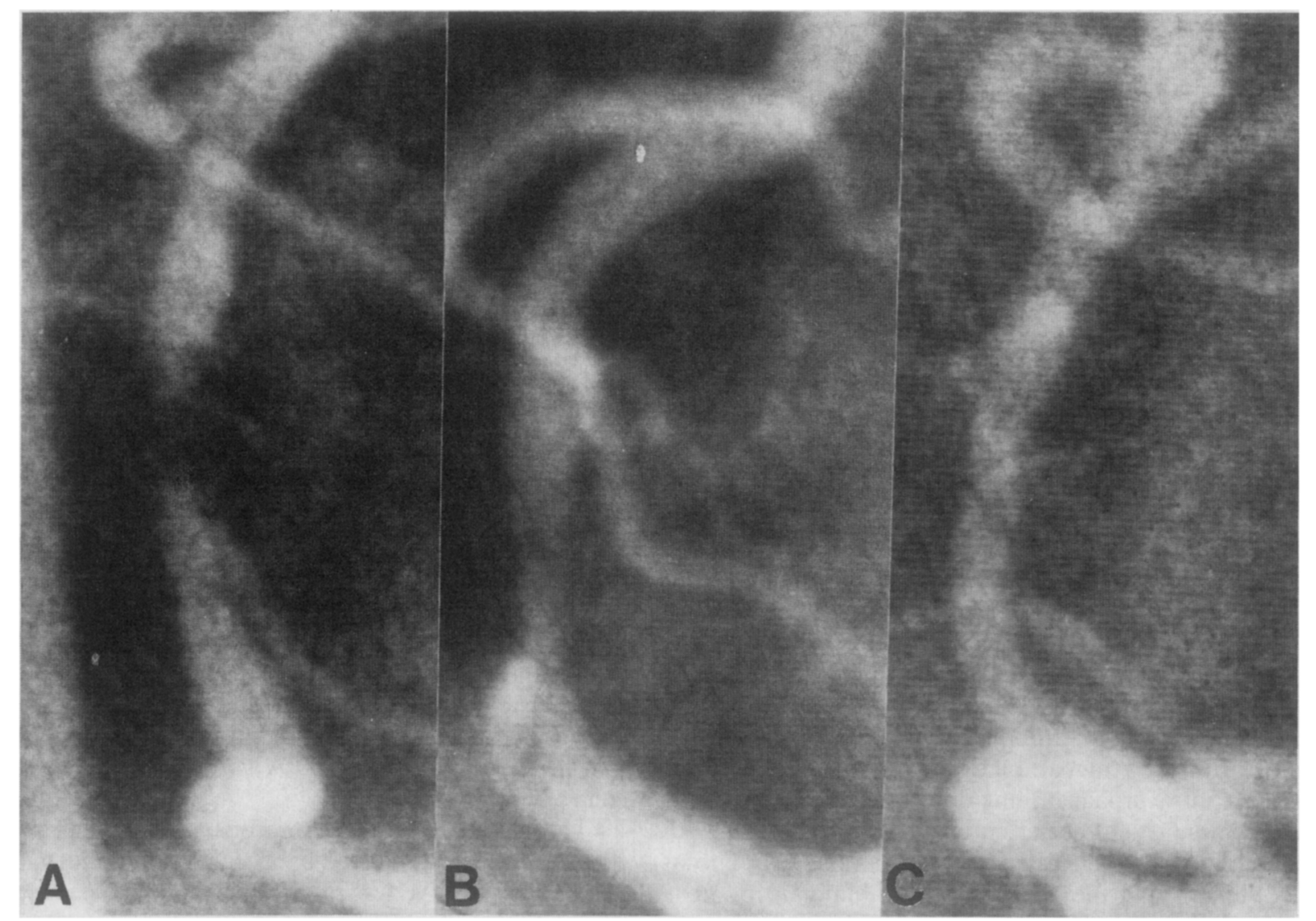

FIGURE 1. Serial angiograms of a patient with unstable angina who was allocated to receive t-PA therapy. A, large filling defect is noted in the midzone of the right coronary artery in the left anterior oblique. B, following $t-P A$, there is resolution of the filling defect but a residual stenosis is apparent. $C$, after coronary angloplasty, the residual stenosis is minimal. 
ing the unstable angina clinical syndromes, most patients may still requirc coronary revascularization, owing to either incomplete dissolution of thrombus or the underlying high grade atherosclerotic lesion.

Four patients receiving t-PA had severe, protracted ischemia during the course of therapy. Although t-PA was associated with overall improvement of the ischemic pacing threshold, the paradoxical clinical deterioration noted in thesc paticnts may rclate to intraplaque hemorrhage, as described by Waller et al ${ }^{16}$ in patients receiving thrombolytic therapy for acute myocardial infarction or as noted by $\mathrm{Falk}^{4}$ in necropsy specimens occuring in patients with unstable angina. As in acute myocardial infarction, there are likely to be patients with unstable angina and intraluminal thrombus who are resistant to therapy. ${ }^{17}$ No matter the mechanism, it is clear that in patients with ischemic pain at rest and maximal medical therapy, intravenous t-PA therapy does not ensure stabilization and urgent revascularization may be necessary.

Of note, 3 patients without distinctive demographic or angiographic characteristics receiving t-PA had marked angiographic resolution of the culprit lesion and no longer exhibited pacing-induced ischemia. In contrast to the majority of patients we have discussed, this particular group appears to have coronary artery thrombus as the predominant component. Similar findings of angiographic resolution of thrombus in patients with unstable angina were reported by Bates and Mickelson ${ }^{18}$ with long-term aspirin therapy. Although such patients who derive marked benefit from fibrinolytic therapy may be uncommon and difficult to identify prospectively, avoidance of unnecessary revascularization procedures as permitted in this study would be highly desirable.

The results of the current study also support the potential for t-PA facilitation of the safety of PTCA for unstable angina. Avoidance of abrupt closure and the need for emergency CABG in t-PA-treated patients may have resulted from dissolution of intraluminal thrombus. Previous studies from the Mayo Clinic group of investigators ${ }^{11,19}$ have confirmed the importance of angiographically defined thrombus as a risk factor for abrupt closure. Review of the published series of PTCA in unstable angina patients suggests a relatively high rate of myocardial infarction, emergency $C A B G$ and inhospital mortality. ${ }^{8-10,13,20-25}$ Besides the acknowledged higher risk of acute complications in these patients, there is an increased rate of restenosis after PTCA for unstable compared with stable angina, which may also relate to coronary artery thrombus. ${ }^{26}$ Thus, further clinical investigation to consider improved safety of PTCA with t-PA appears warranted.

\section{REFERENCES}

1. Kruskal JB, Commerford PJ, Franks JJ, Kirsch RE. Fibrin and fibrinogenrelated antigens in patients with stable and unstable coronary artery disease. $N$ Engl J Med 1987;317:1361 1365.

2. Capone G, Wolf NM, Meyer B, Meister SG. Frequency of intracoronary filling defects by angiography in angina pectoris at rest. Am $\mathrm{J}$ Cardiol 1985:56:403-406.

3. Sherman CT, Litvack F, Grundfest W, Lee M, Hickey A, Chaux A, Kass R,
Blanche C, Matloff J, Morgenstern L, Ganz W, Swan HJC, Forrester J. Coronary angioscopy in patients with unstable angina pectoris. $N$ Engl J Med 1986;315:913-919.

4. Falk E. Unstable angina with fatal outcome: dynamic coronary thrombosis leading to infarction and/or sudden death. Circulation 1985;71:699-708.

5. Rentrop P, Blanke H, Karsch KR, Kaiser H, Kostering H, Leitz K. Selective intracoronary thrombolysis in acute myocardial infarction and unstable angina pectoris. Circulation 1981,63:307-316.

6. Ambrose JA. Monsen C, Borrico S, Sherman W, Cohen M, Gorlin R, Fuster $V$. Ineffectiveness of intracoronary streptokinase in non- $Q$ wave infarction and unstable angina (abstr). Circulation 1986,74(suppl):1I-305

7. Gold HK, Johns JA, Leinbach RC, Yasuda T, Grossbard E, Zusman R, Collen D. A randomized, blinded, placebo-controlled trial of recombinant human tissue-type plasminogen activator in patients with unstable angina pectoris. Circulation 1987,75:1192-1199

8. Williams DO, Riley RS, Singh AK, Gewirtz H, Most AS. Evaluation of the role of coronary angioplasty in patients with unstable angina pectoris. Am Heart $J$ 1981;102:1-9.

9. Meyer J, Bocker B, Erbel R, Bardos P, Messmer BJ, Effert S. Treatment of unstable angina with percutaneous transluminal coronary angioplasty (PTCA) Circulation 1980,62:160-166.

10. de Feyter PJ, Serruys PW, van den Brand W, Balakumaran K, Mochtar B Soward AL, Arnold AER, Hugenholtz PG. Emergency coronary angioplasty in refractory unstable angina. $N$ Engl $J$ Med 1985;313:342-346.

11. Mabin TA, Holmes DR Jr, Smith HC, Vlietstra RE, Bove AA, Reeder GS, Chesebro JH, Bresnaham JF, Orsulak TA. Intracoronary thrombus: role in coronary occlusion complicating percutaneous transluminal coronary angioplasty. JACC 1985:5:198-202.

12. Collen D, Stassen JM, Verstraete M. Thrombolysis with human exirinsic (tissue-type) plasminogen activator in rabbits with experimental jugular vein thrombosis. J Clin Invest 1983;71:368-376.

13. Wohlgelernter D, Cleman M, Highman HA, Zaret BL. Percutaneous transluminal coronary angioplasty of the "culprit lesion" for management of unstable angina pectoris in patients with multivessel coronary artery disease. Am J Cardiol 1986:58:460-464

14. Mancini GBJ, Simon SB, McGillem MJ, LeFree MT, Friedman HZ, Vogel RA. Automated quantitative coronary arteriography: morphologic and physiologic validation in vivo of a rapid digital angiographic method. Circulation 1987;75:452-460.

15. Nicklas JM, Topol EJ, Kander N, Walton JA, Gorman L, Pitt B. Randomized double-blind, placebo-comtrolled trial of $r t-P A$ in unstable angina (abstr) Circulation 1987;76(suppl IV):IV.103I

16. Waller BF, Bothbaum DA, Pinkerton CA, Cowley MJ, Linnemeier TJ, Orr C, Irons M, Helmuth RA, Wills ER, Aust C. Status of the myocardium and infarct-related coronary artery in 19 necropsy patients with acute recanalization using pharmacologic (streptokinase, r-tissue plasminogen activator), mechanical (percutaneous transluminal coronary angioplasty) or combined types of reperfusion therapy. JACC 1987,9:785-801.

17. Califf, RM, Topol EJ, George BS, Boswick J, Lee KL, Stump D, Dillon J, Abbottsmith C, Candela R, Kereiakes D, O'Neill W, Stack RS, and the TAMI Study Group. Characteristics and outcume of patients in whom reperfusion with intravenous tissue-type plasminogen activator fails: results of the thrombolysis and angioplasty in myocardial infarction (TAMI) I trial. Circulation 1988; 77:1090-1099.

18. Bates ER, Mickelson JK. Dissolution of angiographically detected intracoronary thrombus for unstable angina pectoris after aspirin therapy. Am J Cardiol 1987.60:728-729.

19. Sugrue D, Holmes DR Jr, Smith HC, Reeder GS, Lane GE, Vlietstra RE, Bresnahan JF. Coronary artery thrombus as a risk factor for acute vessel occlusion during percutaneous transluminal coronary angioplasty: improving results. Br Heart J 1986:56:62-66.

20. Faxon DP, Detre KM, McCabe CH, Fisher L, Holmes DR, Bowley MJ, Bourassa MG, van Raden M, Ryan TJ. Role of percutaneous transluminal coronary angioplasty in the trealment of unstable angina. Am $J$ Cardiol 1983:53:131C-135C

21. Quigley PJ, Erwin J, Maurer BJ, Walsh MJ, Gearty GF. Percutaneous transluminal coronary angioplasty in unstable angina: comparison with stable angina. Br Heart J 1986;55:227-230.

22. Meyer J, Schmitz H, Erbel R, Kiesslich T, Bocker-Josephs B, Krebs W, Braun PC, Bardos P, Minale C, Messmer BJ, Effert S. Treatment of unstable angina pectoris with percutaneous transluminal coronary angioplasty (PTCA). Cathet Cardiovasc Diagn 1981;7:361-371.

23. Plokker HWST, Ernst JMPG, Vermeulen FEE, Bal ET, Ascoop CAPL. Percutaneous transluminal coronary angioplasty (PTCA) in patients with unstable angina pectoris refractory to medical therapy: long-term clinical and angiographical results (abstr). Circulation 1986;74(suppl):II-283.

24. Holt GW, Fersh BJ, Holmes DR, Vlietstra RE, Reeder GS, Breshnahan JF, Smith HC. The results of percutaneous transluminal coronary angioplasty in postinfarction angina pectoris (abstr). JACC 1986;7:62A.

25. Timmis AD, Griffin B, Crick JCP, Sowton E. Early percutaneous transluminal coronary angioplasty in the management of unstable angina. Int $J$ Cardiol 1987;14:25-31.

26. Steffenino G. Meier B, Finci L. Rutishauser W. Follow up results of treatment of unstable angina by coronary angioplasty. Br Heart J 1987;57:416-419. 